Check for updates

Cite this: RSC Adv., 2019, 9, 34227

Received 15th August 2019

Accepted 7th October 2019

DOI: $10.1039 / c 9 r a 06383 h$

rsc.li/rsc-advances

\section{Divergent synthesis of a thiolate-based $\alpha-$ hydroxytropolone library with a dynamic bioactivity profile $\uparrow$}

\author{
Nana B. Agyemang, (D) ab Cassandra R. Kukla, ${ }^{c}$ Tiffany C. Edwards, ${ }^{c}$ Qilan Li, ${ }^{c}$ \\ Madison K. Langen, ${ }^{d}$ Alexandra Schaal, ${ }^{d}$ Abaigeal D. Franson, ${ }^{c}$ \\ Andreu Gazquez Casals, ${ }^{c}$ Katherine A. Donald, ${ }^{c}$ Alice J. Yu, ${ }^{c}$ Maureen J. Donlin, (iD d \\ Lynda A. Morrison, (D) ce John E. Tavis ID ${ }^{c}$ and Ryan P. Murelli (D) *ab
}

\begin{abstract}
Here we describe a rapid and divergent synthetic route toward structurally novel $\alpha H T$ s functionalized with either one or two thioether or sulfonyl appendages. Evaluation of this library against hepatitis $B$ and herpes simplex virus, as well as the pathogenic fungus Cryptococcus neoformans, revealed complementary biological profiles and new lead compounds with sub-micromolar activities against each pathogen and high selectivities when compared to mammalian cell lines.
\end{abstract}

\section{Introduction}

$\alpha$-Hydroxytropolone ( $\alpha \mathrm{HT}, 1$, Fig. 1A) is a highly oxygenated troponoid with 3 contiguous oxygen atoms that give it the capacity to coordinate two metals in the active sites of many dinuclear metalloenzymes. ${ }^{1}$ As such, it has been of interest as a metal-binding fragment in a broad range of drug-development pursuits. $^{2}$ One of the major obstacles historically associated with exploiting $\alpha \mathrm{HT}$ in drug development, however, has been a scarcity of methods capable of producing functionalized variants. ${ }^{3}$ As a result, most of what is known about the activity of $\alpha$ HTs has stemmed from natural products, and in particular $\beta$ thujaplicinol (2), ${ }^{4}$ a simple natural product variant with a fairly promiscuous activity profile (e.g. , Fig. 1B). ${ }^{5}$ In addition, the few synthetic chemistry-driven structure-function studies that have been conducted have generally focused on highly structurally homologous molecules. ${ }^{6}$

Driven by this need, over the last several years our lab has been studying an oxidopyrylium cycloaddition/ring-opening route to generate a diverse range of $\alpha$ HTs (Scheme 1). ${ }^{7}$ This strategy is highly effective at installing a variety of

${ }^{a}$ Department of Chemistry, Brooklyn College, The City University of New York, Brooklyn, New York 11210, USA. E-mail: rpmurelli@brooklyn.cuny.edu

${ }^{b}$ PhD Program in Chemistry, The Graduate Center of The City University of New York, New York, New York 10016, USA

'Department of Molecular Microbiology and Immunology, Saint Louis University School of Medicine, Saint Louis, Missouri 63104, USA

${ }^{d}$ Edward A. Doisy Department of Biochemistry and Molecular Biology, Saint Louis University School of Medicine, St. Louis, Missouri, 63104, USA

${ }^{e}$ Department of Internal Medicine, Saint Louis University School of Medicine, St. Louis, Missouri, 63110, USA

$\dagger$ Electronic supplementary information (ESI) available. See DOI: 10.1039/c9ra06383h functionalities at position 4 (inset, Scheme 1). However, installing functionality at the 3 position, adjacent to the metalbinding oxygens, is more laborious using this strategy, ${ }^{8}$ and it is not clear at present how the method could install functionality at both the 3- and 6- positions. Given this proximity, it would be expected that molecules with appendages at the 3 and/or 6 positions would more readily engage protein targets either positively or negatively, and as a result have a more dynamic biological activity profile. Thus, strategies that can conveniently install groups at these positions would be complementary to existing synthetic strategies, and as such would be valuable in the continued development of $\alpha$ HT-based therapeutics.

Here we describe the divergent synthesis and biological evaluation of a library of new $\alpha$ HTs that have thioether and sulfonyl appendages at one or both of these positions (Scheme 2B). The thioether-appended $\alpha \mathrm{HTs}$ are synthesized through a rapid halogenation/thiolate addition sequence and are then oxidized to generate an additional set of sulfonyl-containing $\alpha$ HTs. Profiling the library against three common pathogenic microbes, hepatitis B virus (HBV), herpes simplex virus-1 (HSV-

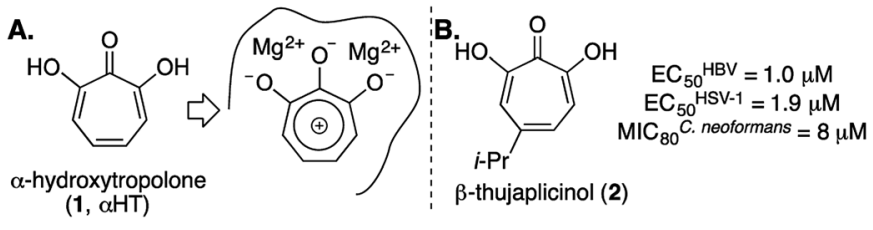

Fig. $1 \alpha$-Hydroxytropolone $(\alpha \mathrm{HT})$ overview. (A) $\alpha \mathrm{HT}$ and potential mode of inhibition of dinuclear metalloenzymes. (B) aHT natural product $\beta$-thujaplicinol, and previously published data against HBV, HSV-1, and C. neoformans. ${ }^{5}$ 
<smiles>COc1ccc(O)c(OC)c1</smiles>
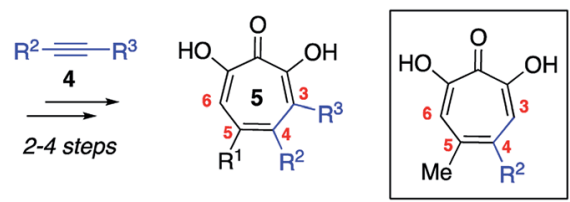

Scheme 1 Oxidopyrylium cycloaddition/ring-opening strategy for $\alpha \mathrm{HT}$ synthesis. Inset is a structure representative of a high percentage of current library made through this approach.

1) and Cryptococcus neoformans (C. neoformans), establishes the dynamic and complementary bioactivity profile that exists among accessible molecules, and provides new lead scaffolds with sub-micromolar activity that should serve as new starting points for drug-development pursuits.

\section{Results and discussion}

\section{Synthesis}

Our synthetic strategy was largely inspired by a halogenation/ cross-coupling sequence exploited by Piettre and co-workers in the synthesis of a series of mono- and bis-arylated 3,7-dihydroxytropolones (Scheme 2A). ${ }^{9}$ Given the value of the strategy in accessing one or both sites adjacent to the metal-binding oxygen triad, we became curious if a similar route might be useful in generating $\alpha$ HTs functionalized at similar positions. Rather than aryl-aryl cross-coupling chemistry, however, we decided to investigate thiolate addition chemistry. Thiolate addition chemistry had been established for halo tropolone functionalization, ${ }^{\mathbf{1 0}}$ and the ability to oxidize to the sulfonyl would provide an additional $\alpha \mathrm{HT}$ analogues with different electronic properties. Furthermore, given our desire to keep the synthesis as simple as possible, we also wanted to avoid the latestage tropolone protection used in the Piettre studies. In this regard, it was known that thiolates could react as nucleophiles in the presence of unprotected $\alpha \mathrm{HTs}^{6}{ }^{6}$

aHT 1 was thus synthesized on multigram scale in 4 steps from tropolone employing a method closely derived from that developed by Takeshita. ${ }^{\mathbf{1 1}}$ Piettre had previously described in-

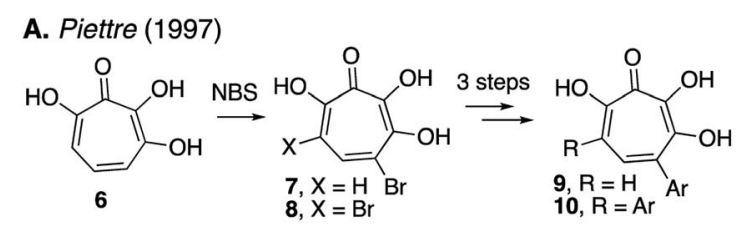

B. This Work

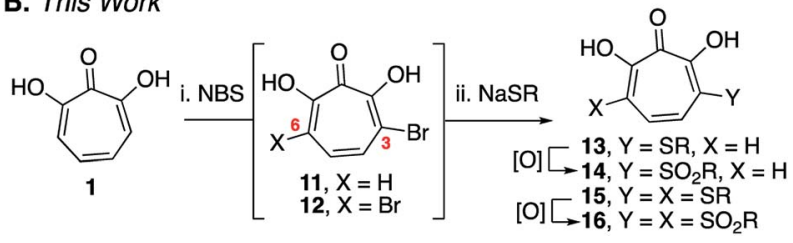

Scheme 2 Halogenation/functionalization approaches to substituted tropolones. (A) Halogenation/cross-coupling strategy to functionalize 3,7-dihydroxytropolones. ${ }^{9}$ (B) Halogenation/thiolate addition/oxidation strategy described herein. depth the challenges of 3,7-dihydroxytropolone monohalogenation for production of 7 due to the high bishalogenated product $\mathbf{8}$, and in order to maximize production of 7 used slow addition of $\mathrm{N}$-bromosuccinimide (NBS) and only took the reaction to partial conversion. ${ }^{9}$ We decided instead to embrace the combinatorial chemistry-type benefits this nonselective halogenation provided. After exploration of various halogenation conditions, we found that refluxing a solution of 1 and 2 equivalents of $N$-bromosuccinimide in benzene over a period of $24 \mathrm{~h}$ yielded a mixture of 7 and 8 in a roughly equimolar ratio. Rather than purify at this step, upon evaporation of the benzene, we immediately added sodium thiolates in DMSO to the reaction vessel and heated the reaction mixture to $80{ }^{\circ} \mathrm{C}$ for $24 \mathrm{~h}$. Upon cooling, the DMSO solution was loaded directly onto a C18 reverse phase column (Biotage Isolera Prime, C18 SNAP) and chromatographed to isolate pure monoand bis-thioether hydroxytropolones, 13a-h and 15a-h. These $\alpha$ HTs were individually converted into mono- and bis-sulfones 14a-h and 16a-h following oxidation with mCPBA. ${ }^{12}$ Thus, we found that from $\alpha \mathrm{HT} 1$ and single thiol or thiolate, we could readily access as many as 4 unique $\alpha$ HTs in only 3 steps.

This chemical sequence was performed with 8 different sodium thiolates, which included aliphatic (entry 1-4), aromatic (entries 5-7), and a benzyl thiolate (entry 8) (Scheme 3). All 16 monosubstituted thioether (13a-h)- and sulfonyl (14ah)-containing $\alpha$ HTs were successfully generated. On the other hand, only 9 of the 16 disubstituted $\alpha$ HTs were successfully made and purified. One of the limitations to the procedure was the addition of the aromatic thiolates, which did not provide the corresponding bis thiolates cleanly $(\mathbf{1 5 e}-\mathbf{g})$, even when attempting to make them from purified dibrominated $\alpha \mathrm{HT} \mathbf{1 2 .}$ It is unclear why these specific molecules were problematic, but our inability to generate them meant that we were also unable to access the bis sulfonyl compounds of this series $(\mathbf{1 6 e - g})$. One other molecule that we were unable to generate was $16 \mathbf{a}$. Nonetheless, even without having access to this subset of molecules, we were able to rapidly generate 25 unique $\alpha$ HTs from 1 and $\mathbf{8}$ thiolates.

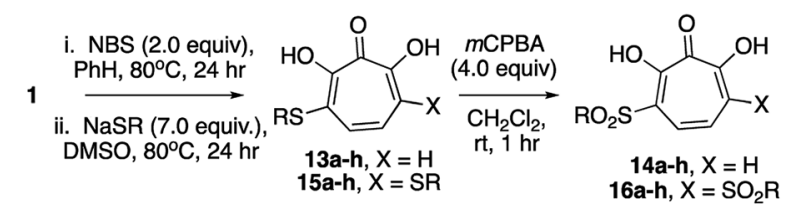

\begin{tabular}{|c|c|c|c|c|}
\hline \multirow{2}{*}{$\frac{\text { entry }}{1}$} & \multirow{2}{*}{$\begin{array}{l}\mathrm{R}= \\
\mathrm{Me}\end{array}$} & \multirow{2}{*}{$\begin{array}{c}\text { Step } 1(\% \text { yield from } 6)^{a} \\
55 \%(13 a, 31 \% ; 15 a, 24 \%)\end{array}$} & \multicolumn{2}{|c|}{$\begin{array}{l}\text { Step } 1(\% \text { yield from } 13 \text { or } \\
\left.\mathbf{1 5}^{\mathrm{a}}\right)^{\mathrm{a}}\end{array}$} \\
\hline & & & $14 a(72 \%)$ & $16 \mathbf{a}(0 \%)$ \\
\hline 2 & $n-\mathrm{Bu}$ & $30 \%(13 b, 15 \% ; 15 b, 15 \%)$ & $14 \mathrm{~b}(63 \%)$ & $16 \mathrm{~b}(30 \%)$ \\
\hline 3 & $n$-Hex & $50 \%(13 c, 19 \% ; 15 c, 31 \%)^{b}$ & $14 c(62 \%)$ & $16 c(97 \%)$ \\
\hline 4 & $i-\operatorname{Pr}$ & $81 \%(13 d, 14 \% ; 15 d, 67 \%)$ & $14 d(49 \%)$ & $16 d(42 \%)$ \\
\hline 5 & $\mathrm{Ph}$ & $27 \%(13 e, 27 \% ; 15 e, 0 \%)$ & $14 \mathrm{e}(25 \%)$ & - \\
\hline 6 & 1-Npth & $19 \%(13 f, 19 \% ; 15 f, 0 \%)$ & $14 f(48 \%)$ & - \\
\hline 7 & 4-Tolyl & $16 \%(13 \mathrm{~g}, 16 \% ; 15 \mathrm{~g}, 0 \%)$ & $14 \mathrm{~g}(42 \%)$ & - \\
\hline 8 & $\mathrm{Bn}$ & $44 \%(13 \mathrm{~h}, 13 \% ; 15 \mathrm{~h}, 31 \%)^{b}$ & $14 \mathrm{~h}(45 \%)$ & $16 \mathrm{~h}(59 \%)$ \\
\hline
\end{tabular}

Scheme 3 Synthesis of thioether and sulfonyl $\alpha \mathrm{HTS}$. ${ }^{\text {alsolated yields }}$ following C18-capped silica gel chromatography. ${ }^{\mathrm{b}}$ Thiolates made and used in situ from sodium hydride and the corresponding thiol. See ESI $\dagger$ for detail. 


\section{Biological studies}

Overview. With our library of tropolones in hand we assessed the biological activity against three human pathogens known to be susceptible to $\alpha \mathrm{HTs}$ : HBV ${ }^{5 \boldsymbol{a}, 13} \mathrm{HSV}-1,{ }^{5 b, 14}$ and $C$. neoformans ${ }^{5 c}$ (See Fig. 1 for details). The human hepatoblastoma cell line HepDES $19^{15}$ is the host cell for the HBV antiviral studies and is more susceptible to $\alpha$ HT cytotoxicity than Vero cells, ${ }^{13}$ which serve as the host cell for HSV-1 antiviral studies. For this reason cytotoxicity of the library against HepDES19 was also measured for all molecules to gauge general mammalian cell cytotoxicity. A complete listing of the data from these experiments can be found in the ESI, $\dagger$ and an overview of these results can be viewed in Fig. 2. The data are presented as a heat diagram to emphasize the differences in the profiles of the molecules, and representative new leads are also shown. A descriptive discussion of the activity of the library against each pathogen, as well as its significance for drug-development, follows.

Herpes simplex virus-1. HSV-1 is a common double-stranded DNA virus most closely associated with painful and embarrassing cold sores ${ }^{\mathbf{1 6}}$ and genital lesions. ${ }^{1}$ In addition, the virus causes herpetic stromal keratitis, a painful inflammation of the cornea with a global incidence rate of 1.5 million per year, 40000 cases of which result in visual impairment or blindness. ${ }^{17}$ Although less frequent, when HSV-1 spreads to the central nervous system, it can cause life-threatening herpetic encephalitis in adults and in babies infected during birth. ${ }^{18}$ Current anti-HSV therapy employs nucleos(t)ide analogs which are incompletely effective ${ }^{18 b}$ and lead to drug-resistance. ${ }^{18 c}$ New treatment options for HSV-1 infections are thus of high interest.

$\alpha$ HTs have been identified as potent inhibitors of the virus, with measured effective concentrations for $50 \%$ viral replication suppression $\left(\mathrm{EC}_{50}\right.$ ) as low as $50 \mathrm{nM}$ (Fig. 3$) .{ }^{8}$ While studies are ongoing to establish the likely mechanism of action, certain $\alpha \mathrm{HTs}$ are known to inhibit at least two HSV-1 nucleases, $\mathrm{UL}^{15}{ }^{19}$ and $\mathrm{UL} 12{ }^{20}$ and also act synergistically with current antivirals. ${ }^{14} \alpha$ HTs also have demonstrable activity against other herpesviruses including human cytomegalovirus ${ }^{5 b}$ and Kaposi's sarcoma-associated herpesvirus, ${ }^{21}$ as well as several animal herpesviruses. ${ }^{22}$ For all these reasons, the continued development of $\alpha \mathrm{HTs}$ as antiviral agents against HSV-1 is warranted.

The 25 thiolate-based $\alpha$ HTs were thus screened in plaque reduction assays at concentrations of $5 \mu \mathrm{M}, 1 \mu \mathrm{M}$, and $0.33 \mu \mathrm{M}$. From this screen, 6 molecules were found to suppress viral replication by at least 10 -fold at a concentration of $1 \mu \mathrm{M}$ (See Fig. 2 and the ESI $\dagger$ ). These molecules each share a common set of 3 thioether-based appendages, $n$-butyl, $n$-hexyl and benzyl thioether. Of these molecules, the 3 bis-thioether compounds of the series $(\mathbf{1 5 b} / \mathbf{c} / \mathbf{h})$ maintained significant inhibitory activity at $0.33 \mu \mathrm{M}$. Additional experiments with these 6 molecules were carried out to obtain more quantitative $\mathrm{EC}_{50}$ values (Table 1). Consistent with the screening findings, the bis-thioether molecules $\left(\mathrm{EC}_{50}=0.08-0.26 \mu \mathrm{M}\right)$ were more potent than their corresponding mono-thioether congeners $\left(\mathrm{EC}_{50}=0.59-1 \mu \mathrm{M}\right)$. While 15c and 15h were among the more cytotoxic molecules when tested against HepDES19 cells $\left(\mathrm{CC}_{50}=\sim 8 \mu \mathrm{M}\right)$, they

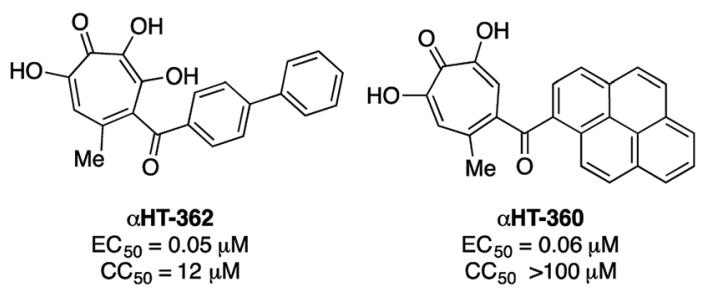

Fig. 3 Representative examples of potent anti-HSV-1 $\alpha$ HTs previously tested. ${ }^{8,23}$.

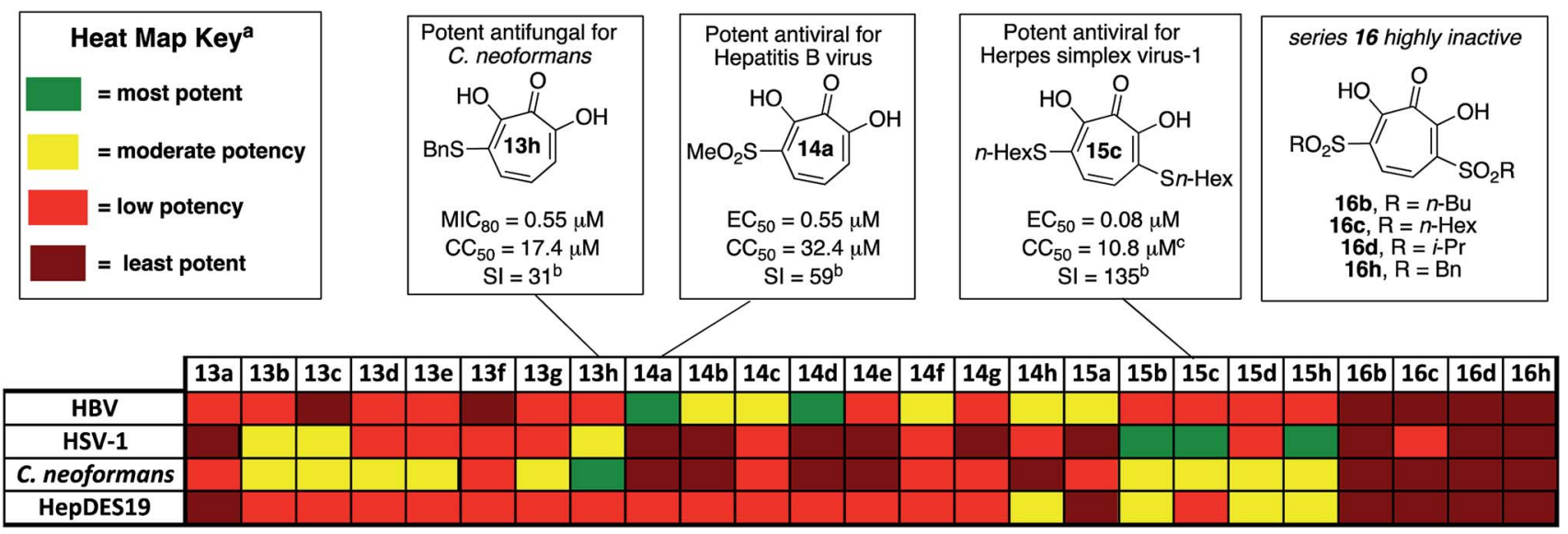

Fig. 2 Overview of biological activity of thiolate-base $\alpha \mathrm{HT}$ library against a panel of pathogenic microbes. ${ }^{\mathrm{a}}$ For HBV antiviral activity and HepDES19 cytotoxicity, potency is judged based on $50 \%$ effective inhibitory concentrations ( $\mathrm{EC}_{50}$ ) for HBV antiviral activity, and $50 \%$ cytotoxicity concentrations $\left(\mathrm{CC}_{50}\right)$ for HepDES19 cytotoxicity: most potent $<1.0 \mu \mathrm{M}$; moderate potency $=1.0-10 \mu \mathrm{M}$; least potency $>49 \mu \mathrm{M}$. For HSV potency is judged by whether the molecules showed 10 -fold or greater replication inhibition at different concentrations: most potent $=$ effective at 0.33 $\mu \mathrm{M}$; moderate potency $=$ effective at $1.0 \mu \mathrm{M}$; low potency $=$ effective at $5.0 \mu \mathrm{M}$; least potent are inactive at $5.0 \mu \mathrm{M}$. For $\mathrm{C}$. neoformans, potency is judged based on $80 \%$ minimum growth inhibition $\left(\mathrm{MIC}_{80}\right)$ : most potent $<1.0 \mu \mathrm{M}$; moderate potency $=1.0-10 \mu \mathrm{M}$; low potency $=10-49 \mu \mathrm{M}$; least potent $>49 \mu \mathrm{M} .{ }^{\mathrm{b}} \mathrm{I}=$ selectivity index, defined as $\mathrm{CC}_{50} / \mathrm{MIC}_{80}$ for $13 \mathrm{~h}$, or $\mathrm{CC}_{50} / \mathrm{EC}_{50}$ for $14 \mathrm{a}$ and $15 \mathrm{c}$. ${ }^{\circ} \mathrm{Cytotoxicity} \mathrm{value} \mathrm{shown} \mathrm{for} \mathrm{HepDES19.} 15 \mathrm{c}$ is not cytotoxic against host Vero cell line at up to $100 \mu \mathrm{M}$ for 48 hours. 
Table 1 Anti-HSV-1 effective concentration at $50 \%$ inhibition ( $E_{50}$ ) of select $\alpha \mathrm{HTs}$, along with $50 \%$ cytotoxic concentration $\left(\mathrm{CC}_{50}\right)$ in Vero cells

\begin{tabular}{|c|c|c|c|}
\hline & $\begin{array}{c}13 \mathrm{~b}, \mathrm{R}=n-\mathrm{Bu} \\
13 \mathrm{c}, \mathrm{R}=n-\mathrm{Hex} \\
13 \mathrm{~h}, \mathrm{R}=\mathrm{Bn}\end{array}$ & $\begin{array}{c}15 b, R=n-B u \\
15 c, R=n-H e x \\
15 h, R=B n\end{array}$ & \\
\hline Cmpd & $\mathrm{EC}_{50} \pm \mathrm{SE}^{a}(\mu \mathrm{M})$ & $\mathrm{CC}_{50} \pm \mathrm{SE}^{a}(\mu \mathrm{M})$ & $\operatorname{clog} P^{b}$ \\
\hline $13 b$ & $1.01 \pm 0.32$ & $>100$ & -0.93 \\
\hline $13 c$ & $0.93 \pm 0.08$ & $>100$ & 0.13 \\
\hline $13 h$ & $0.59 \pm 0.06$ & $>100$ & -0.95 \\
\hline $15 b$ & $0.26 \pm 0.06$ & $87.2 \pm 4.6$ & 1.23 \\
\hline $15 c$ & $0.08 \pm 0.00$ & $>100$ & 3.35 \\
\hline $15 \mathrm{~h}$ & $0.08 \pm 0.02$ & $>100$ & 1.19 \\
\hline
\end{tabular}

${ }^{a} \mathrm{EC}_{50}$ and $\mathrm{CC}_{50}$ values calculated from the average of 3 runs \pm standard error. ${ }^{b} \operatorname{cog} P$ values calculated in monoanionic state using ChemDraw Professional, version 15.0.

showed no cytotoxicity at up to $100 \mu \mathrm{M}$ against Vero cells, which were the host cell line for the anti-HSV-1 assays. Thus, 15c and 15d, have cell-based activity profiles on par with the most potent anti-HSV-1 $\alpha$ HTs developed to date, and as such reveal an alternative starting point for further optimization studies.

In addition to the new leads that emerged, the totality of the structure-function studies also provided additional insight that could be useful in guiding further optimization. Recently, we disclosed an $\alpha$ HT-based structure-activity relationship (SAR) based upon oxidopyrylium cycloaddition/ring-opening approach to the molecules that found that lipophilicity (as determined in the monoanionic state by $\operatorname{clog} P$ ) correlates highly with potent anti-HSV activity, with some secondary trends illustrating the potential importance of side-chain rigidity. ${ }^{23}$ The SAR of the thiolate-based $\alpha \mathrm{HT}$ library revealed some trends consistent with this activity. Compounds $\mathbf{1 5 b} / \mathbf{c} / \mathbf{h}$ had the highest $\operatorname{cog} P$ values of the thiolate-based library, and were the only three compounds with $\operatorname{cog} P$ values in the monoanionic state exceeding 1 . 15c was by far the most lipophilic molecule ( $\operatorname{cog} P=3.35$, Table 1 ), and was one of the two most potent molecules, along with 15h. 15h had comparable clog $P$ value to 15b, but was 4 times more potent. This could be the result of the rigidity of the aromatic appendage, which further restricts the number of rotatable bonds when compared to $\mathbf{1 5 b}$. Similar increases in potency can be observed in the monothioether series (13h vs. 13b). It is worth noting, however, that 1-napthyl-containing thioether, 13f, is both more lipophilic ( $\operatorname{cog} P=0.44$ ) and more rigid than $\mathbf{1 3 h}$, and yet is inactive at 1 $\mu \mathrm{M}$. One hypothesis to explain this discrepancy is that some flexibility is needed to achieve proper contact with the target enzyme. Structure-function studies on this new library provide additional trends that appear to confirm the importance of both lipophilicity and rigidity in the design of more potent $\alpha \mathrm{HT}$ - based anti-HSV-1 agents. This information should help guide future optimization studies on the molecules.

Cryptococcus neoformans. Cryptococcus neoformans is a fungal pathogen known to cause deadly Cryptococcal meningitis, mostly in immunocompromised individuals. The fungus is particularly prevalent in HIV/AIDS patients, and recent estimates are that $15 \%$ of all AIDS-related deaths globally are the result of Cryptococcal meningitis, ${ }^{24}$ ranking second behind only tuberculosis. The disease is particularly problematic in sub-Saharan Africa, where most recent reports estimate roughly 160000 new cases of Cryptococcal meningitis and 140000 Cryptococcal meningitis-related deaths per year. Cryptococcal infections are also common in solid organ transplant patients, with estimates of $3 \%$ of the population developing fungal infections within the first year, and patients remaining at high risk of infection for 5 years. ${ }^{25}$ When left untreated, 1 year mortality rates from Cryptococcal meningitis range from $30 \%$ to $100 \%$, depending on the region. While antifungal agents such as amphotericin B and fluconazole can be effective, the prognosis for survival among treated patients remains poor $(20 \%$ to $70 \%$, depending on region). Furthermore, these drugs have significant toxicity issues associated with them. Thus, the development of new classes of antifungal agents targeting $C$. neoformans is of high interest.

A recent survey of troponoids against $C$. neoformans revealed that $\alpha \mathrm{HT} 1$ had modest inhibition on the growth of $C$. neoformans, with an $80 \%$ minimum growth inhibition concentration $\left(\mathrm{MIC}_{80}\right)$ of $24 \mu \mathrm{M} .^{5 c}$ In addition to this molecule, 35 substituted $\alpha$ HTs were also evaluated, but none of these molecules was substantially more potent (Fig. 4 and Fig. 1). By contrast, when the 25-membered thiolate-based $\alpha \mathrm{HT}$ library was tested for its ability to inhibit $C$. neoformans growth, ten different molecules had $\mathrm{MIC}_{80}$ values below $10 \mu \mathrm{M}$ (Table 2 and Fig. 2). This library of potent molecules was specific to the thioether series (13 and 15) and included all but the methyl thiolate-based molecules 13a and 15a, and naphthyl thiolate-containing $\alpha$ HT 13f. Given that 13a had a $\mathrm{MIC}_{80}$ value equal to 1, it appears that the sulfur portion of the appendage may play very little role in these activity increases. The most potent molecule of the series contained a single benzylthioether $\left(\mathbf{1 3 h}, \mathrm{MIC}_{80}=0.55 \mu \mathrm{M}\right)$, and this molecule was 50 times more potent than $\alpha \mathrm{HT} 1$. The presence of a second thioether $\left(\mathbf{1 5 h}, \mathrm{MIC}_{80}=7 \mu \mathrm{M}\right)$, or replacement of the thioether with the analogous sulfone $\left(\mathbf{1 4 h}, \mathrm{MIC}_{80}=50 \mu \mathrm{M}\right)$ was deleterious to the activity. $\mathbf{1 3 h}$ had relatively moderate cytotoxicity against HepDES19 cells $\left(\mathrm{CC}_{50}=17 \mu \mathrm{M}\right)$, giving the molecule a selectivity index over 30 . This value was over 6 times

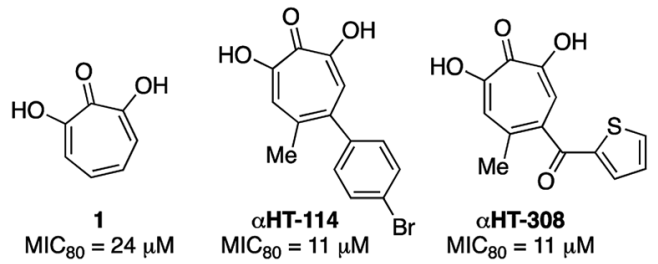

Fig. 4 Previously described $\alpha \mathrm{HTS}$ with $C$. neoformans antifungal activity. $^{5 c}$ 
Table 2 Minimal concentration for $80 \%$ growth inhibition $\left(\mathrm{MIC}_{80}\right)$ of thiolate-based $\alpha H T s$. Values are reported as the average of 2 runs, with the exception of $13 \mathrm{~b}$ and $13 \mathrm{~h}$, which are the average of 3 runs

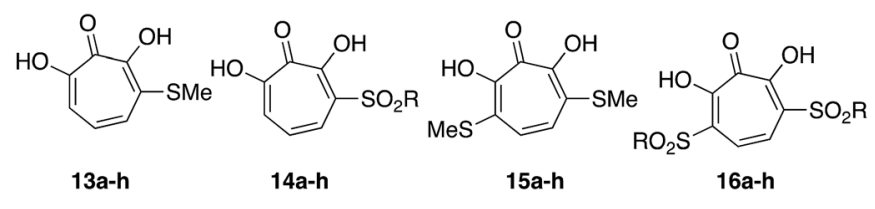

C. neoformans growth inhibition $\left(\mathrm{MIC}_{80}\right)$

\begin{tabular}{lllll} 
& \multicolumn{1}{l}{ 13a-h } & 14a-h & 15a-h & 16a-h \\
\hline $\mathrm{R}=\mathrm{Me}$ & $\mathbf{1 3 a}(28 \mu \mathrm{M})$ & $\mathbf{1 4 a}(50 \mu \mathrm{M})$ & $\mathbf{1 5 a}(38 \mu \mathrm{M})$ & - \\
$\mathrm{R}=n$-Bu & $\mathbf{1 3 b}(1 \mu \mathrm{M})$ & $\mathbf{1 4 b}(50 \mu \mathrm{M})$ & $\mathbf{1 5 b}(2.3 \mu \mathrm{M})$ & $\mathbf{1 6 b}(100 \mu \mathrm{M})$ \\
$\mathrm{R}=n$-Hex & $\mathbf{1 3 c}(1.7 \mu \mathrm{M})$ & $\mathbf{1 4 c}(14 \mu \mathrm{M})$ & $\mathbf{1 5 c}(7 \mu \mathrm{M})$ & $\mathbf{1 6 c}(50 \mu \mathrm{M})$ \\
$\mathrm{R}=i$-Pr & $\mathbf{1 3 d}(2.6 \mu \mathrm{M})$ & $\mathbf{1 4 d}(50 \mu \mathrm{M})$ & $\mathbf{1 5 d}(1.5 \mu \mathrm{M})$ & $\mathbf{1 6 d}(100 \mu \mathrm{M})$ \\
$\mathrm{R}=\mathrm{Ph}$ & $\mathbf{1 3 e}(1.5 \mu \mathrm{M})$ & $\mathbf{1 4 e}(50 \mu \mathrm{M})$ & - & - \\
$\mathrm{R}=1-\mathrm{Npth}$ & $\mathbf{1 3 f}(21 \mu \mathrm{M})$ & $\mathbf{1 4 f}(38 \mu \mathrm{M})$ & - & - \\
$\mathrm{R}=4$-tolyl & $\mathbf{1 3 g}(1.7 \mu \mathrm{M})$ & $\mathbf{1 4 g}(38 \mu \mathrm{M})$ & - & - \\
$\mathrm{R}=\mathrm{Bn}$ & $\mathbf{1 3 h}(0.55 \mu \mathrm{M})$ & $\mathbf{1 4 h}(50 \mu \mathrm{M})$ & $\mathbf{1 5 h}(7 \mu \mathrm{M})$ & $\mathbf{1 6 h}(73 \mu \mathrm{M})$
\end{tabular}

greater than any of the synthetic $\alpha$ HTs previously tested. ${ }^{5 c}$ Thus, 13h represents a substantial breakthrough for $C$. neoformanstargeting $\alpha$ HT-based antifungals. Furthermore, the structurefunction data and synthetic strategy presented provide knowledge and opportunities that should be valuable for additional optimization studies.

Hepatitis B virus. Hepatitis B virus (HBV) is the most common cause of chronic hepatic infection worldwide, and is responsible for over 800000 deaths annually. ${ }^{26}$ While the HBV vaccine is renowned for its success at curbing new hepatitis $B$ cases, nearly 300 million people remain chronically infected worldwide. For these individuals, who have a $20-30 \%$ chance of developing cirrhosis and/or liver cancer due to HBV, current therapies based on interferon $\alpha$ or nucleos(t)ide analogs reduce death from hepatocellular carcinoma by only $2-4$ fold $^{5 c}$ and there is no cure. Thus, a major goal is to establish treatments that can yield durable elimination of viremia and halt disease progression following a limited-duration treatment regimen (a "functional cure"). ${ }^{27}$ As part of this effort, many research labs are trying to identify novel hepatitis B antivirals that profoundly suppress viral replication by attacking viral functions not targeted by the current drugs, ${ }^{28}$ probably through combination therapy with currently available antivirals. ${ }^{29} \alpha$ HTs have been identified as potent anti-HBV agents, and $\alpha \mathrm{HT} 1$ has an $\mathrm{EC}_{50}$ of $1.7 \mu \mathrm{M}$, and no cytotoxicity against HepDES19 cells at up to 100 $\mu \mathrm{M} .^{13}$ Several synthetic derivatives have been identified with nearly 5 -fold potency increases over $\mathbf{1}$, including compound aHT-110 (Fig. 5), which also suppresses HBV viremia in an animal model. ${ }^{30}$ We hypothesized that electron-withdrawing groups on the $\alpha \mathrm{HT}$ could improve potency by stabilizing a dianionic state that may exist when the $\alpha \mathrm{HT}$ is bound to the target enzyme, which is believed to be the dinuclear metalloenzyme HBV ribonuclease $\mathrm{H}$ (RNaseH). ${ }^{31}$ Thus, the thiolate-based library provided us with an opportunity to probe this structure-function activity relationship in more detail.

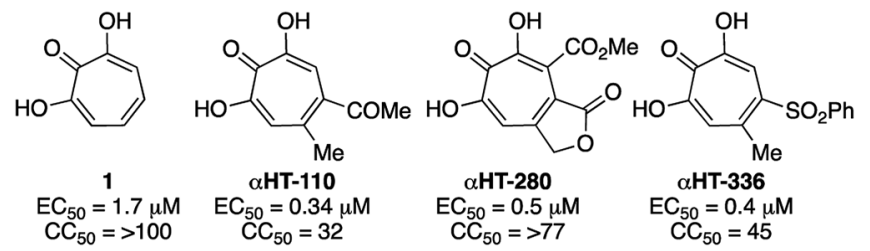

Fig. 5 Representative examples of previously described anti-HBV $\alpha \mathrm{HTs}$. $\left(E_{50}\right)$ along with cytotoxicity against HepDES19 cells $\left(C_{50}\right) \cdot{ }^{13}$

Of the 25 thiolate-based $\alpha$ HTs, most of the molecules $(23 / 25)$ had activity far less than $\mathbf{1}$ (Table 3 ). The two with improved activity were the two mono-sulfone-containing $\alpha$ HTs with the smallest appendages, 14a and 14d, and these were roughly 2fold more potent than $1\left(\mathrm{EC}_{50}=0.55 \mu \mathrm{M}\right.$ and $0.79 \mu \mathrm{M}$, respectively, Table 3). Unlike 1 and some of the top leads, these molecules had moderate cytotoxicity against HepDES19 cells $\left(\mathrm{CC}_{50}=32 \mu \mathrm{M}\right.$ and $20 \mu \mathrm{M}$, respectively), but their selectivity indexes for HBV compared to the host cell line remained strong (59 and 25, respectively). Given our prior SAR suggesting that improved activity could be achievable by adding more electronwithdrawing capabilities, ${ }^{\mathbf{1 3 b}}$ we had expected that the bissulfonyl series (16a-h) would be the most potent series tested. However, these molecules were all inactive. Given that the bisthioether series (15a-h) were generally more active than the mono-thioether series (13a-h), it was initially suspected that the rapid drop in activity may be the result of electronic or cellpermeability differences rather than sterics. Compound 16d has a highly negative $\operatorname{cog} P$ value in the monoionic state (see Table 4), and it is possible that the electron-withdrawing appendages may increase the acidity of the molecules to the point that it would exist primarily in a dianionic state at physiological $\mathrm{pH},{ }^{32}$ lowering its permeability even further. This may also help explain the lack of activity of series $\mathbf{1 6}$ in all other cell types tested herein.

Thus, we became interested in assessing how a series of $\alpha$ HTs (13d-16d) might behave in biochemical assays where cellpermeability would not influence activity. It was postulated that if 16d was highly active biochemically, this would support the hypothesis that the lack of activity was due to low cell permeability. As stated earlier, the cell-based HBV antiviral activity of $\alpha \mathrm{HT}$ is believed to be the result of $\mathrm{RNaseH}$ inhibition, which is supported by the presence of an RNaseH-deficient phenotype in cells treated with ribonuclease $\mathrm{H}$ inhibitors such as those tested here. $^{5 a}$ An HBV RNaseH enzyme inhibition assay is available, although it is often the case that potent antiviral activity does not correlate well with enzymatic inhibition, which may be the result of the recombinant $\mathrm{RNaseH}$ protein being only part of the larger HBV polymerase protein..$^{33}$ Thus, in addition to evaluating HBV $\mathrm{RNaseH}$ activity, we also tested the molecules for inhibition of human RNaseH1 and E. Coli RNaseH to more broadly evaluate the trend of $\mathrm{RNaseH}$ inhibition in relationship to molecule class. When the series of molecules was tested against these enzymes, however, we found that $\mathbf{1 6 \mathbf { d }}$ was the least active against the entire series. Thus, we cannot conclude that the lack of activity of series $\mathbf{1 6}$ is due to a lack of cell permeability. 
Table 3 HBV antiviral activity of thiolate-based $\alpha \mathrm{HT}$, as measured by effective concentration at $50 \%$ viral suppression $\left(E_{50}\right)$. Values are reported as either single a single run, or, for more potent molecules, the average of 2 runs. See Table S1 in ESI, including standard deviation

$\begin{array}{lllll} & \\ & & \end{array}$

Table 4 Ribonuclease $H$ inhibition data for series $13 d-16 d$. Also included are previously measured $\mathrm{p} K_{\mathrm{a}}$ values ${ }^{32}$ and clog $P$ values, as determined with ChemDraw Professional 15.0 in the monoanionic state

$$
\text { ↔ }
$$

\begin{tabular}{llllllll}
\hline & \multicolumn{2}{l}{ RNase H Inhibition $\left(\mathrm{IC}_{50}, \mu \mathrm{M}\right)$} & & \multicolumn{2}{c}{ Acidity $\left(\mathrm{p} K_{\mathrm{a}}\right)$} & \\
\cline { 2 - 3 } Cmpd & Human & E. Coli & HBV & & $\mathrm{p} K_{\mathrm{a} 1}$ & $\mathrm{p} K_{\mathrm{a} 2}$ & $\operatorname{clog} P$ \\
\hline 13d & $62 \pm 19$ & $2.4 \pm 0.6$ & $184 \pm 27$ & & 5.9 & $>12$ & -1.67 \\
14d & $125 \pm 18$ & $52 \pm 3$ & $103 \pm 13$ & 3.8 & 11 & -2.84 \\
15d & $238 \pm 44$ & $3.5 \pm 1.0$ & $112 \pm 8$ & & 4.8 & $>12$ & -0.27 \\
16d & $>500$ & $90 \pm 2$ & $254 \pm 26$ & 2.2 & 7.6 & -3.35
\end{tabular}

\section{Conclusions}

A divergent synthetic strategy is described that provides rapid access to a library of 25 functionalized $\alpha$ HTs from the parent $\alpha \mathrm{HT}$ 1 and 8 thiolates. Profiling this library against three human pathogens (HBV, HSV and C. neoformans), as well as a human hepatoblastoma (HepDES19) revealed a dynamic activity profile, and unique new leads with sub-micromolar activity for each of the pathogens. These studies represent a new synthetic strategy to identify novel opportunities for developing $\alpha$ HTs as drug fragments, as well as structure-function insight to help guide them.

\section{Conflicts of interest}

MJD, LAM, JET, and RPM are co-inventors on a patent describing $\alpha$ HTs as drug leads for the three diseases described herein.

\section{Author contributions}

MJD, NBA and RPM synthesized and characterized library of molecules. CRK, RCE, QL, and JET obtained hepatitis B antiviral and HepDES19 cytotoxicity data. MKL, AS, and MJD obtained $C$. neoformans antifungal data. ADF, AGC, KAD, AJY, and LAM obtained herpes simplex virus-1 antiviral and Vero cytotoxicity data. RPM wrote manuscript, with primary input and assistance from NBA, MJD, LAM, and JET. Vero cells were a gift from Dr David Knipe (Harvard University), HepDES19 Cells were a gift from Dr Haitao Guo (Indiana University), and C. neoformans wild-type KN99 $\alpha$ was a gift from Dr Jennifer Lodge (Washington University).

\section{Acknowledgements}

The authors acknowledge funding from the National Institutes of Health in the form of research grants awarded to RPM (SC1GM111158) and JET (R01AI122669). LAM appreciates support from the Pershing Trust. MJD received support from the Saint Louis University Presidential Research Fund. We thank Elena Lomonosova and Austin O'Dea for technical assistance.

\section{Notes and references}

1 C. Meck, M. P. D' Erasmo, D. R. Hirsch and R. P. Murelli, The biology and synthesis of $\alpha$-hydroxytropolones, MedChemComm, 2014, 5, 842-852.

2 For a few lead examples, see: (a) S. R. Piettre, A. Ganzhorn, J. Hoflack, K. Islam and J. M. Hornsperger, $\alpha$ Hydroxytropolones: a new class of potent inhibitors of inositol monophosphatase and other bimetallic enzymes, $J$. Am. Chem. Soc., 1997, 119, 3201-3204; (b) N. E. Allen, W. E. Alborn Jr, J. N. Hobbs Jr and J. H. A Kirst, 7Hydroxytropolones: an inhibitor of aminoglycoside $2^{\prime \prime}-O$ adenyltransferase, Antimicrob. Agents Chemother., 1982, 22, 824-831; (c) S. R. Budihas, I. Gorshkova, S. Gaidamakov, A. Wamiru, M. K. Bona, M. A. Parniak, R. J. Crouch, J. B. McMahon, J. A. Beutler and S. F. J. Le Grice, Selective inhibition of HIV-1 reverse transcriptase-associated ribonuclease $\mathrm{H}$ activity by hydroxylated tropolones, Nucleic Acids Res., 2005, 33, 1249-1256.

3 (a) M. G. Banwell and M. P. Collis, The palladium-mediated cross-coupling of bromotropolones with organostannanes; application to concise syntheses of $\beta$-dolabrin, $\beta$ thujaplicin, 7-methoxy-4-isopropyltropolones, and $\beta$ thujaplicinol, J. Chem. Soc., Chem. Commun., 1991, 13431345; (b) J. Zinser, S. Henkel and B. Fohlisch, A novel synthesis of 2-alkoxy-3-hydroxytropones and 2,7dihydroxytropones from dialkoxy- 8-oxabicyclo[3.2.1] oct-6en-3-ones, Eur. J. Org. Chem., 2004, 1344-1346; (c) T. Yamatani, M. Yasunami and K. Takase, Dehydrotropolones: a benzyne-type Intermediate in the reaction of halotropolones with alkoxides, Tetrahedron Lett., 1970, 11, 1752-1758. 
4 A. B. Anderson and J. Gripenberg, Antibiotic substances from the heart wood of Thuja plicata D. Don, Acta Chem. Scand., 1948, 2, 644-650.

5 For HBV, see: (a) Y. Hu, X. Cheng, F. Cao, A. Huang and J. E. Tavis, $\beta$-Thujaplicinol inhibits hepatitis $B$ virus replication by blocking the viral ribonuclease $\mathrm{H}$ activity, Antivir. Res., 2013, 99, 221-229. For HSV-1, see: (b) J. E. Tavis, H. Wang, A. E. Tollefson, B. Ying, M. Korom, X. Cheng, F. Cao, K. L. Davis, W. S. M. Wold and L. A. Morrison, Inhibitors of nucleotidyltransferase superfamily enzymes suppress herpes simplex virus replication, Antimicrob. Agents Chemother., 2014, 58, 74517461. For C. neoformans, see: (c) M. J. Donlin, A. Zunica, A. Lipnicky, A. K. Garimallaprabhakaran, A. J. Berkowitz, A. Grigoryan, M. J. Meyers, J. E. Tavis and J. R. P. Murelli, Troponoids can inhibit growth of the human fungal pathogen Cryptococcus neoformans, Antimicrob. Agents Chemother., 2017, 61, e02574-16.

6 (a) J. Didierjean, C. Isel, F. Querre, J. F. Mouscadet, A. M. Aubertin, J. Y. Valnot, S. R. Piettre and R. Marquet, Inhibition of human immunodeficiency virus type 1 reverse transcriptase, RNase $\mathrm{H}$, and integrase activities by hydroxytropolones, Antimicrob. Agents Chemother., 2005, 49, 4884-4894; (b) S. Chung, D. M. Himmel, J. K. Jiang, K. Wojtak, J. D. Bauman, J. W. Rausch, J. A. Wilson, J. A. Beutler, C. J. Thomas, E. Arnold and S. F. J. Le Grice, Synthesis, activity, and structural analysis of novel $\alpha$ hydroxytropolone inhibitors of human immunodeficiency virus reverse transcriptase-associated ribonuclease $\mathrm{H}, J$. Med. Chem., 2011, 54, 4462-4473.

7 For lead reference, see: C. Meck, N. Mohd and R. P. Murelli, An oxidopyrylium cyclization/ring-opening route to polysubstituted $\alpha$-hydroxytropolones, Org. Lett., 2012, 14, 5988-5991.

8 For a representative example, see: D. R. Hirsch, D. V. Schiavone, A. J. Berkowitz, L. A. Morrison, T. Masaoka, J. A. Wilson, E. Lomonosova, H. Zhao, B. S. Patel, S. H. Dalta, S. J. Majidi, R. K. Pal, E. Gallicchio, L. Tang, J. E. Tavis, S. F. J. Le Grice, J. A. Beutler and R. P. Murelli, Synthesis and biological assessment of 3,7dihydroxytropolones, Org. Biomol. Chem., 2018, 16, 62-69.

9 S. R. Piettre, C. Andre, M. C. Chanal, J. B. Ducep, B. Lesur, F. Piriou, P. Raboisson, J. M. Rondeau, C. Schelcher, P. Zimmermann and A. J. Ganzhorn, Monoaryl- and bisaryldihydroxytropolones as potent inhibitors of inositol monophosphatase, J. Med. Chem., 1997, 40, 4208-4221.

$10 \mathrm{~K}$. Kubo and A. Mori, "Synthesis and mercurophilic properties of acyclic and thiolariat ethers having tropone pendant", Heterocycles, 2001, 54, 351-358.

$11 \mathrm{H}$. Takeshita; M. Akira; and K. Tomoyuka, "An improved synthesis of 2,7-dihydroxytropone (3-hydroxytropolone)" synthesis, 1986, pp. 578-579.

12 K. Hassenberg, J. Pickardt and R. Steudel, Oxidation products of 1,2,3-trithia [3] ferrocenophane: structures of the corresponding sulfoxide and sulfone, Organometallics, 2000, 19, 5244-5246.
13 (a) G. Lu, E. Lomonosova, X. Cheng, E. A. Moran, M. K. Meyers, S. F. J. Le Grice, C. J. Thomas, J.-K. Jiang, C. Meck, D. R. Hirsch, M. P. D'Erasemo, D. M. Suyabatmaz, R. P. Murelli and J. E. Tavis, Hydroxylated tropolones inhibit hepatitis $\mathrm{B}$ virus replication by blocking the viral ribonuclease $\mathrm{H}$ activity, Antimicrob. Agents Chemother., 2015, 59, 1070-1079; (b) E. Lomonosova, J. Daw, A. K. Garimallaprabhakaran, N. B. Agyemang, Y. Ashani, R. P. Murelli and J. E. Tavis, Efficacy and cytotoxicity in cell culture of novel $\alpha$ hydroxytropolone inhibitors of hepatitis $B$ virus ribonuclease H, Antiviral Res., 2017, 144, 164-172.

14 P. J. Ireland, J. E. Tavis, M. P. D'Erasmo, D. R. Hirsch, R. P. Murelli, M. M. Cadiz, B. S. Patel, A. K. Gupta, T. C Edwards, M. Korom, E. A. Moran and L. A. Morrison, Synthetic $\alpha$-hydroxytropolones inhibit replication of wildtype and acyclovir-resistant herpes simplex viruses, Antimicrob. Agents Chemother., 2016, 60, 2140-2149.

15 H. Guo, D. Jiang, T. Zhao, A. Cuconati, T. M. Block and J.-T. Guo, Characterization of the intracellular deproteinized relaxed circular DNA of hepatitis B virus: an intermediate of covalently closed circular DNA formation, J. Virol., 2007, 81, 12472-12484.

16 R. J. Whitley, Herpes simplex viruses, in Fields Virology, D. Knipe and P. Howley, Lippincott Williams \& Wilkins, Philadelphia, PA, 4th edn, 2001, vol. 2, pp. 2461-2509.

17 A. V. Farooq and D. Shukla, Herpes simplex epithelial and stromal keratitis: an epidemiologic update, Surv. Ophthalmol., 2012, 57, 448-462.

18 (a) R. J. Whitley, Herpes simplex encephalitis: adolescents and adults, Antiviral Res., 2006, 71, 141-148; (b) C. Johnston, M. Saracino, S. Kuntz, A. Magaret, S. Selke, M. L. Huang, J. T. Schiffer, D. M. Koelle, L. Corey and A. Wald, Standard-dose and high-dose daily antiviral therapy for short episodes of genetal HSV-2 reactivation: three randomized, open-label, cross-over trails, Lancet, 2012, 379, 641-647; (c) R. Duan, R. D. de Vries, A. D. Osterhaus, L. Remeijer and G. M. Verjans, Acyclovirresistant corneal HSV-1 isolates from patients with herpetic keratitis, J. Infect. Dis., 2008, 198, 659-663.

19 T. Masaoka, H. Zhao, D. R. Hirsch, M. P. D'Erasmo, C. Meck, B. Varnado, A. Gupta, M. J. Meyers, J. D. Baines, J. A. Beutler, R. P. Murelli, L. Tang and S. F. J. Le Grice, Characterization the C-terminal nuclease domain of herpes simplex virus pUL15 as a target of nucleotidyltransferase inhibitors, Biochemistry, 2016, 55, 809-819.

20 L. M. Grady, R. Szczepaniak, R. P. Murelli, T. Masaoka, S. F. J. Le Grice, D. L. Wright and S. K. Weller, The exonuclease activity of HSV-1 UL12 is required for the production of viral DNA that can be packaged to produce infectious virus, J. Virol., 2017, 91, e01380-17.

21 J. T. Miller, H. Zhao, T. Masaoka, B. Varnado, E. M. Cornejo Castro, V. A. Marshall, K. Kouhestani, A. Y. Lynn, K. E. Aron, A. Xia, J. A. Beutler, D. R. Hirsch, L. Tang, D. Whitby, R. P. Murelli and S. F. J. Le Grice, Sensitivity of the Cterminal nuclease domain of Kaposi's Sarcoma-associated 
herpesvirus ORF29 to two classes of active site ligands, Antimicrob. Agents Chemother., 2018, 62, e00233-18.

22 S. D. Dehghanpir, C. H. Birkenheuer, K. Yang, R. P. Murelli, L. A. Morrison, S. F. J. Le Grice and J. D. Baines, Broad antiherpesviral activity of $\alpha$-hydroxtropolones, Vet. Microbiol., 2018, 214, 125-131.

23 A. J. Berkowitz, A. D. Franson, A. Gazquez Cassals, K. A. Donald, A. J. Yu, A. K. Garimallaprabhakaran, L. A. Morrison and R. P. Murelli, Importance of lipophilicity for potent antiherpes simplex virus-1 activity of $\alpha$-hydroxytropolones, MedChemComm, 2019, 10, 1173-1176.

24 R. Rajasingham, R. M. Smith, B. J. Park, J. N. Jarvis, N. P. Govender, T. M. Chiller, D. W. Denning, A. Loyse and D. R. Boulware, "Global burden of disease of HIVassociated cryptococcal meningitis: an updated analysis”, Lancet Infect. Dis., 2017, 17, 873-881.

25 D. Neofytos, J. A. Fishman, D. Horn, E. Anaissie, C. H. Chang, A. Olyaei, M. Pfaller, W. J. Steinbach, K. M. Webster and K. A. Marr, Epidemiology and outcome of invasive fungal infections in solid organ transplant recipients" Transpl, Lancet Infect. Dis., 2010, 12, 220-229.

26 W. H. O., Hepatitis B: World Health Organization Fact Sheet. https://www.who.int/news-room/fact-sheets/detail/hepatitisb accessed June 4, 2019.

27 (a) B. Sebastien, B. Leda, E. Maryam and R. F. Schinazi, "Towards elimination of hepatitis B virus using novel drugs, approaches, and combined modalities", Clin. Liver Dis., 2016, 20, 737-749; (b) A. P. Revill, F. V. Chisari, J. M. Block, M. Dandri, A. J. Gehring, H. Guo, J. Hu, A. Kramvis, P. Lampertico, H. L. A. Janssen, M. Levrero, W. Li, T. J. Liang, S. G. Lim, F. Lu, M. C. Penicaud,
J. E. Tavis, R. Thimme, Members of the I. C. E.-H. B. V. Working Groups, I. C. E.-H. B. V. Stakeholders Groups Chairs, I. C. E.-H. B. V. Senior Advisors and F. Zoulim, A global scientific strategy to cure hepatitis $\mathrm{B}$, The Lancet Gastroenterology \& Hepatology, 2019, 4, 545-558.

28 S. Feng, L. Gao, X. Han, T. Hu, Y. Hu, H. Liu, A. W. Thomas, Z. Yan, S. Yang, J. A. T. Young, H. Yun, W. Zhu and H. C. Shen, Discovery of small molecule therapeutics for treatment of chronic HBV infection, ACS Infect. Dis., 2018, 4, 257-277.

29 J. S. Emery and J. J. Feld, Treatment of hepatitis B virus with combination therapy now and in the future, Best Pract. Res. Clin. Gastroenterol., 2017, 31, 347-355.

30 K. R. Long, E. Lomonosova, W. Li, N. L. Ponzar, J. A. Villa, E. Touchette, S. Rapp, R. M. Liley, R. P. Murelli, A. Grigoryan, R. M. Buller, L. Wilson, J. Bial, J. E. Sagartz and J. E. Tavis, Efficacy of hepatitis B virus ribonuclease $\mathrm{H}$ inhibitors, a new class of replication antagonists, in FRG human liver chimeric mice, Antiviral Res., 2018, 149, 41-47. 31 J. E. Tavis, G. Zoidis, M. J. Meyers and R. P. Murelli, Chemical approaches to inhibiting the hepatitis $\mathrm{B}$ virus ribonuclease H, ACS Infect. Dis., 2019, 5, 655-658.

32 J. P. Stasiak, A. Grigoryan and R. P. Murelli, Spectrophotometric determination of $\alpha$-hydroxytropolone pKa values, Tetrahedron Lett., 2019, 60, 1643-1645.

33 T. C. Edwards, E. Lomonosova, J. A. Patel, Q. Li, J. A. Villa, A. K. Gupta, L. A. Morrison, F. Bailly, P. Cotelle, E. Giannakopoulou, G. Zoidis and J. E. Tavis, Inhibition of hepatitis B virus replication by $\mathrm{N}$-hydroxyisoquinolinediones and related polyoxygenated heterocycles, Antiviral Res., 2017, 143, 205-217. 